\title{
A Fuzzy Multi Criteria Approach for Evaluating Sustainability Performance of Third - Party Reverse Logistics Providers
}

\author{
Nadine Kafa, Yasmina Hani, and Abederrahman El Mhamedi \\ Equipe MGSI/ LISMMA - Université de Paris8, \\ 140, rue de la nouvelle France, 93100 Montreuil, France \\ \{n.kafa,y.hani, a.elmhamedi\}@iut.univ-paris8.fr
}

\begin{abstract}
Due to the complexity and specificity of reverse logistics system, some organizations outsource all or part of the reverse logistics process to third -party provider (3PRLP). The selection of the most efficient 3PRLP is a crucial task in which it is important to take into account environmental and social criteria as well as economic criteria owing to economic interests, stakeholder pressures, and environmental legislations. The tie between all three aspects of sustainability in 3PRLP selection problem has been almost ignored. This research work deals with this issue and develops a new integrated approach for selecting the best sustainable 3PRLP. A hybrid multi-criteria making decision model is structured to assign the priority weights of decision criteria using fuzzy analytic hierarchy process (FAHP) and to get the final ranking of providers using fuzzy preference ranking organization method for enrichment evaluation (F-PROMETHEE). A numerical example is also presented to illustrate the proposed approach.
\end{abstract}

Keywords: Sustainable supply chain, reverse logistics, third-party provider selection, fuzzy AHP, fuzzy PROMETHEE.

\section{Introduction}

Reverse logistics (RL) is defined as a set of elements (collection, sorting, treatment, information system and distribution system) [1] deals with product returns in order to retrieve sustainable values. In today's competitive environment, different organizations take into consideration the management of reverse flows in their supply chain system. According to Kannan et al. [2] dealing with returns is a complicated issue because of the need of specialized infrastructures, the lack of experience, and considerable uncertainties regarding to delivery, quality and quantity of the returned products. Therefore, many organizations decide to outsource reverse logistics function to third-party providers (3PRLPs). On the other hand, the introduction of corporate social responsibility principles and sustainability issues in RL system is a means of developing a complete sustainable performance model [3].

Several studies have discussed sustainability issues and highlighted the importance of achieving the triple bottom line of economic, social, and environmental goals in 
conventional supply chain management [4], green supply chain management [5], reverse logistics [3], and supplier selection [6], while researches consider all three dimensions of sustainable development in 3PRLP selection are rather limited till now. Within supply chain management, the implementation of sustainable initiatives and green practices is difficult without cooperation with all partners in the network. Therefore, selecting right 3PRLPs based on integrated sustainability criteria can assist organizations to improve their sustainability performance. Some of the 3PRLP selection related papers have started paying more attention to this issue. Wang and Zhu [7] proposed a model to solve the problem of selecting an appropriate 3PRLP in environmental viewpoint of low-carbon economy. Tajik et al.[8]developed a hybrid fuzzy AHP-TOPSIS approach for evaluating sustainable 3PRLPs. The framework they proposed is highly stylized. However, there is a real need for research on 3PRLPs selection problem with sustainability concerns because the majority of the present models focuses on economic and slightly on environmental factors. This paper is among the first research works that shed light on this issue. Hence, the main contribution of this paper is to propose a new model for multi-criteria 3PRLP selection problem based on fuzzy AHP-PROMETHEE approach involving sustainability criteria.

The next section presents the hybrid fuzzy AHP-PROMETHEE approach to assess sustainability performance of 3PRLPs. Third section presents an illustrative example and results analysis. Finally, the paper ends with conclusions.

\section{Proposed Model for 3PRL Provider Selection}

Due to 3PRLP selection problem is a complicated MCDM problem and time consuming assignment, a clear process should be required to resolve it. The proposed model is structured to allocate the priority weights of decision criteria by resolving FAHP algorithm and to rank 3PRL providers by resolving F-PROMETHEE algorithm, as illustrated in Fig. (1).

\subsection{Sustainability Decision Criteria}

The key criteria for selecting suitable 3PRLP can typically include cost, quality, and financial performance. Furthermore, indexes of low-carbon and social indicators can play a crucial role in selecting 3PRLPs as the need to coordinate and integrate all the business functions with sustainability considerations. Reverse logistics outsourcing should clearly be economically, environmentally and socially applied. The sustainability criteria and sub-criteria have been defined in detail based on specific literature review in the area of 3PRL provider selection by Kafa et al.[9].

\subsection{Fuzzy AHP Algorithm}

The basic concept of AHP method [10] is to model a general decision problem as a hierarchical structure including sub-problems that can be easily evaluated in order to determine the priorities via pair-wise comparison of the elements at each level of the decision hierarchy. This method has gained popularity observing the amount of 


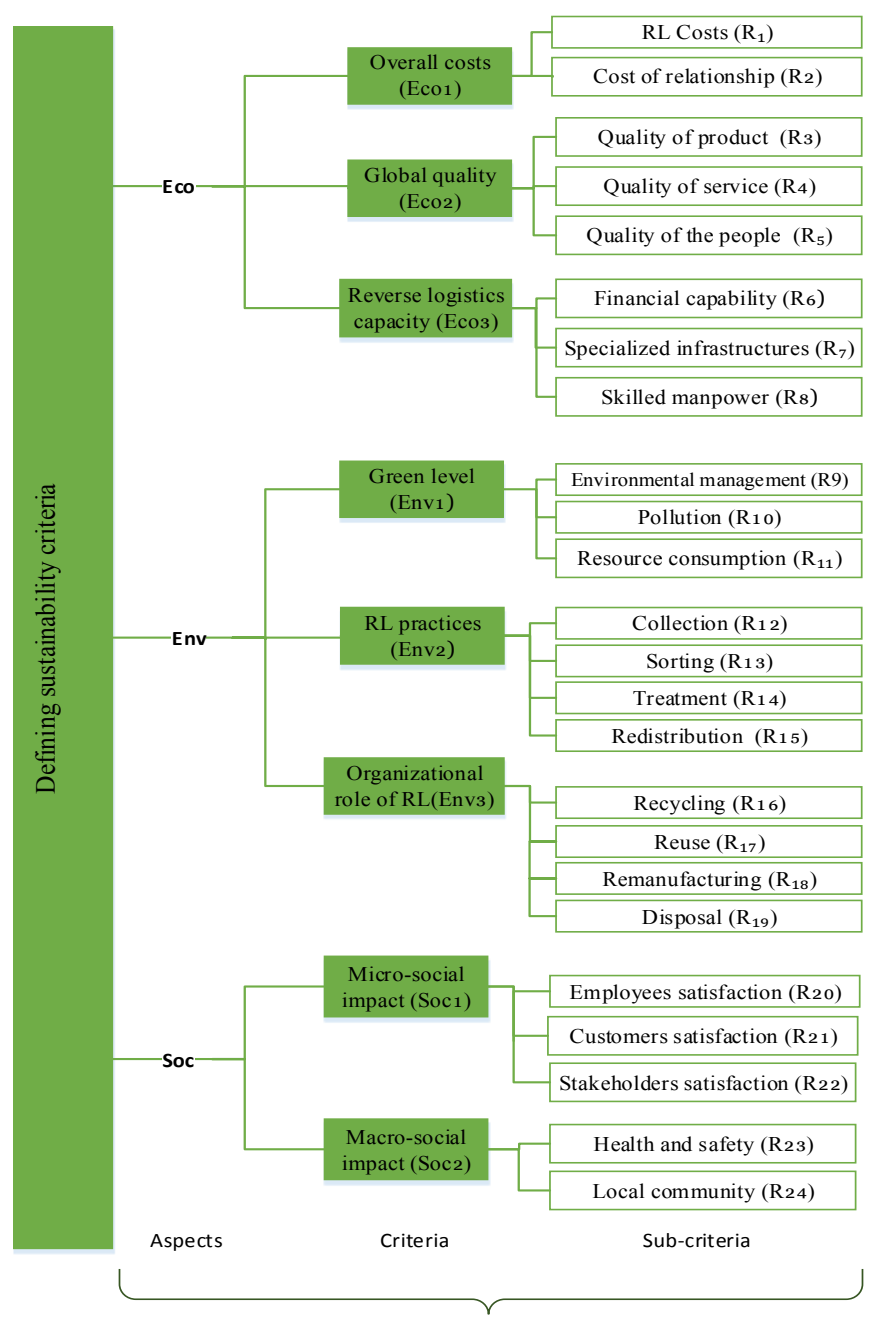

Fuzzy AHP for assigning weights to the decision elements

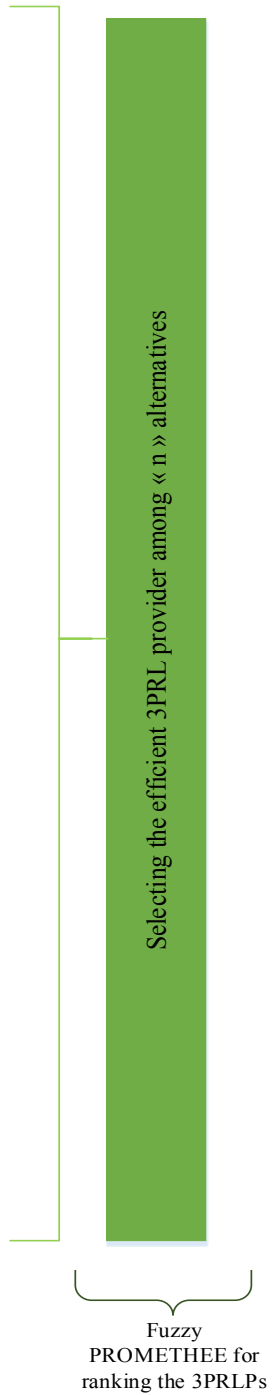

Fig. 1. Proposed fuzzy AHP-PROMETHEE model for selecting the best 3PRL provider

studies that have utilized it including supply chain management. As providers' selection criteria always contain ambiguity and diversity of meaning, the fuzzy AHP algorithm proposed by Kwong and Bai [11] was employed for estimating the weights of selected criteria as follows.

Step 1: Construct the fuzzy judgment matrices (FCMs) for each level. Fuzzy theory set [12] is incorporated with pair-wise comparison in AHP to get more benefit of human reasoning that is approximate rather than precise. The decision maker (DM) 
preference is represented in form of fuzzy pair-wise comparison matrix (FCM) using the linguistic fuzzy scale represents in terms of triangular fuzzy numbers (TFN) (equally $=\mathbb{1}$, moderately $=\stackrel{3}{3}$, strongly $=\breve{5}$, very strongly $=\mathbb{7}$, extremely $=\mathscr{9}$ ).

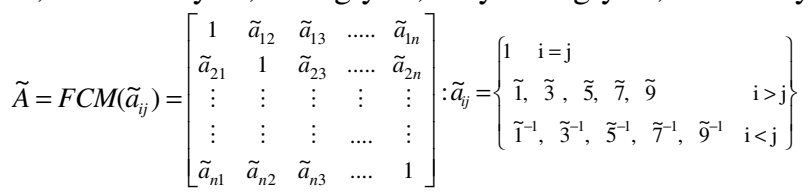

Step 2: Determine the priorities of different decision elements. The prioritization of the elements of each matrix is done by solving fuzzy eigenvalues and eigenvectors. A fuzzy eigenvalue $\tilde{\lambda}$ is a fuzzy number solution to:

$$
\tilde{A} \tilde{x}=\tilde{\lambda} \tilde{x}
$$

: $\tilde{x}$ is a non-zero $\mathrm{n} \times 1$ fuzzy eigenvector containing fuzzy numbers.

The interval arithmetic and the $\alpha$-cuts are introduced to perform fuzzy multiplication and addition. By defining the confidence level $\alpha$ in order to integrate the decision maker (DM) confidence over the judgments [13], the TFN can be illustrated as:

$$
\operatorname{TFN}_{\alpha}=\left[a^{\alpha}, c \alpha\right]=[(b-a) \alpha+a,-(c-b) \alpha+c] \forall \alpha \in[0,1]
$$

For example, with respect to the level $\alpha$, the lower limit and upper limit of the fuzzy numbers $\widetilde{3}^{-1}$ and $\widetilde{3}^{-1}$, can be obtained by applying equation (2).

$$
\tilde{3}_{\alpha}=[1+2 \alpha, 5-2 \alpha], \tilde{3}_{\alpha}^{-1}=[1 /(5-2 \alpha), 1 /(1+2 \alpha)]
$$

The degree of satisfaction for the judgment matrix $\tilde{A}$ is estimated from the DM by the index of optimism $\mu$. The larger value of the index $\mu$ is the higher degree of optimism that is defined as a linear convex combination [13]:

$$
\tilde{a}_{i j}^{\alpha}=\mu \tilde{a}_{i j u}^{\alpha}+(1-\mu) \tilde{a}_{i j l}^{\alpha} \forall \mu \in[0,1]
$$

The eigenvector $\tilde{x}$ is calculated by fixing $\mu$ and substituting the maximal eigenvalue $\lambda \max$ into the equation (1).

Step 3: Calculate the consistency ratio of a matrix $\tilde{A}$ using the mathematical formula $\mathrm{CR}=\mathrm{CI} / \mathrm{RI}$ as explained by Saaty [10]. A CR of $10 \%$ or less is acceptable.

Step 4: Normalize weight vector in order to determine the local and total importance weights $\left(W_{i}\right)$.

Following the above explained steps, the MATLAB package is used to calculate the priority weights of the main aspects, the criteria, and the sub -criteria, (see Table 1.) and then the results are analyzed in the third section.

\subsection{Fuzzy PROMETHEE Algorithm}

The preference ranking organization method for enrichment evaluation (PROMETHEE) is one of the conventional simple outranking methods to resolve 
MCDM problems which is applied in various areas of research. This method was developed by Brans and Vincke [14] based on the exploitation of a valued outranking relation via pair-wise comparisons between the alternatives regarding different criteria. The evaluation table that shows the performance level of each potential alternative for each criterion is required as the first point to apply PROMETHEE method. In this paper, all alternatives (3PRLPs) are evaluated using linguistic scale with corresponding fuzzy numbers $($ TFN) [very $\operatorname{good}=(7,7,9)$, good $=(5,7,9)$, fair $=(3,5,7)$, poor $=$ $(1,3,5)$, very poor $=(1,1,3)]$.The defuzzification of TFNs is done using graded mean integration representation (GMIR) method, proposed by Chen and Hsieh [15]. Where $\mathrm{TFN}=(\mathrm{a}, \mathrm{b}, \mathrm{c})$, the GMIR R(TFN) of TFN is:

$$
R(T F N)=1 / 6(c+4 a+b)
$$

Additional information on priority weights of the criteria is also required which is done using FAHP method in this study, as PROMETHEE method cannot distribute weights to the criteria. The various steps of PROMETHEE can be outlined briefly as follows:

Step 1: Calculate preference function of alternative (a) with regard to alternative (b) in the set of "A" alternatives for each sub-criterion:

$$
P_{i}(a, p)=f_{i}\left[d_{i}(a, b)\right] \quad \forall \mathrm{P}_{\mathrm{i}}(a, p) \in[0,1]
$$

Where $d_{i}(a, b)$ is the difference between the evaluation of "a" and " $\mathrm{b}$ " on ith subcriterion. Several basic preference functions are explained by Brans and Vincke [14] like V-criterion, Gaussian criterion, and U-criterion. In this study, the usual function has been selected which is mostly used with qualitative criteria [16].

Step 2: Calculate outgoing flow and incoming flow for each alternative using equation (6) and equation (7) for ranking the alternatives by a partial preorder "PROMETHEE I" technique that introduces the incomparability between alternatives. Then calculate net flow using equation (8) for ranking the alternatives by a total preorder "PROMETHEE II" technique.

$$
\begin{gathered}
\phi^{+}(a)=1 /(A-1) \sum_{x \in A} \sum_{i=1}^{i} W_{i} P_{i}(a, x) \\
\phi^{-}(a)=1 /(A-1) \sum_{x \in A} \sum_{i=1}^{i} W_{i} P_{i}(x, a) \\
\phi(a)=\phi^{+}(a)-\phi^{-}(a)
\end{gathered}
$$

The Visual PROMETHEE software includes the basic of PROMETHEE method is used to calculate outranking flows and rank the alternatives. 


\section{$3 \quad$ Application and Discussion of Results}

The problem discussed here is related to a manufacturing company wants to implement reverse logistics activities by outsourcing them to 3PRLP. The company desires to consider all the possible key factors which can affect the efficiency of reverse logistics functions. Furthermore, it is important to consider social and environmental as well as economic attributes in 3PRLP selection process in order to achieve sustainable competitive advantage. Currently, the company has four alternatives, namely $\mathrm{RLP}_{1}$, $\mathrm{RLP}_{2}, \mathrm{RLP}_{3}$ and $\mathrm{RLP}_{4}$. To select the right one, the proposed model is applied. The relative importance of each pair of selected criteria is prioritized after asking the global logistics manager as decision maker (DM) in the company concerned to answer a questionnaire including all possible pair-wise comparison.

Table 1. The priority weights of decision criteria

\begin{tabular}{|c|c|c|c|c|c|c|c|}
\hline $\begin{array}{l}\text { Aspects } \\
\text { Weights }\end{array}$ & $\begin{array}{l}\text { Crite- } \\
\text { ria }\end{array}$ & $\begin{array}{l}\text { Local } \\
\text { weights }\end{array}$ & $\begin{array}{l}\text { Total } \\
\text { weights }\end{array}$ & $\begin{array}{l}\text { Sub- } \\
\text { Criteria }\end{array}$ & $\begin{array}{l}\text { Local } \\
\text { weights }\end{array}$ & $\begin{array}{l}\text { Total } \\
\text { weights }\end{array}$ & Consistency \\
\hline \multirow{8}{*}{$\begin{array}{l}\text { ECO } \\
(0,64)\end{array}$} & \multirow[t]{2}{*}{$\mathrm{Eco}_{1}$} & \multirow[t]{2}{*}{0,5076} & \multirow[t]{2}{*}{0,3267} & $\mathrm{R}_{1}$ & 0,5858 & 0,1914 & \multirow{2}{*}{$\begin{array}{l}\lambda_{\max }=2,06 \\
\mathrm{CR}=0.00\end{array}$} \\
\hline & & & & $\mathrm{R}_{2}$ & 0,4142 & 0,1353 & \\
\hline & \multirow[t]{3}{*}{$\mathrm{EcO}_{2}$} & \multirow[t]{3}{*}{0,4014} & \multirow[t]{3}{*}{0,2583} & $\mathrm{R}_{3}$ & 0,1159 & 0,0299 & \multirow{3}{*}{$\begin{array}{l}\lambda_{\max }=3.099 \\
\mathrm{CR}=0.086\end{array}$} \\
\hline & & & & $\mathrm{R}_{4}$ & 0,5294 & 0,1368 & \\
\hline & & & & $\mathrm{R}_{5}$ & 0,3547 & 0,0916 & \\
\hline & \multirow[t]{3}{*}{$\mathrm{EcO}_{3}$} & \multirow[t]{3}{*}{0,091} & \multirow[t]{3}{*}{0,0585} & $\mathrm{R}_{6}$ & 0,2156 & 0,0126 & \multirow{3}{*}{$\begin{array}{l}\lambda_{\max }=3.099 \\
\mathrm{CR}=0,09\end{array}$} \\
\hline & & & & $\mathrm{R}_{7}$ & 0,6436 & 0,0377 & \\
\hline & & & & $\mathrm{R}_{8}$ & 0,1409 & 0,0082 & \\
\hline \multirow{11}{*}{$\begin{array}{l}\text { ENV } \\
(0,22)\end{array}$} & \multirow[t]{3}{*}{ Env $_{1}$} & \multirow[t]{3}{*}{0,7387} & \multirow[t]{3}{*}{0,1593} & $\mathrm{R}_{9}$ & 0,7387 & 0,1176 & \multirow{3}{*}{$\begin{array}{l}\lambda_{\max }=3.061 \\
\mathrm{CR}=0.053\end{array}$} \\
\hline & & & & $\mathrm{R}_{10}$ & 0,7387 & 0,0244 & \\
\hline & & & & $\mathrm{R}_{11}$ & 0,1081 & 0,0172 & \\
\hline & \multirow[t]{4}{*}{$\mathrm{Env}_{2}$} & \multirow[t]{4}{*}{0,1532} & \multirow[t]{4}{*}{0,0330} & $\mathrm{R}_{12}$ & 0,5092 & 0,0168 & \multirow{4}{*}{$\begin{array}{c}\lambda_{\max }=4.21 \\
\mathrm{CR}=0.078\end{array}$} \\
\hline & & & & $\mathrm{R}_{13}$ & 0,0809 & 0,0027 & \\
\hline & & & & $\mathrm{R}_{14}$ & 0,2226 & 0,0074 & \\
\hline & & & & $\mathrm{R}_{15}$ & 0,1872 & 0,0062 & \\
\hline & \multirow[t]{4}{*}{$\mathrm{Env}_{3}$} & \multirow[t]{4}{*}{0,1081} & \multirow[t]{4}{*}{0,0233} & $\mathrm{R}_{16}$ & 0,2654 & 0,0062 & \multirow{4}{*}{$\begin{array}{c}\lambda_{\max }=4.21 \\
\mathrm{CR}=0.078\end{array}$} \\
\hline & & & & $\mathrm{R}_{17}$ & 0,5580 & 0,0130 & \\
\hline & & & & $\mathrm{R}_{18}$ & 0,1200 & 0,0028 & \\
\hline & & & & $\mathrm{R}_{19}$ & 0,0566 & 0,0013 & \\
\hline \multirow{5}{*}{$\begin{array}{l}\text { SOC } \\
(0,14)\end{array}$} & \multirow[t]{3}{*}{ Soc $_{1}$} & \multirow[t]{3}{*}{0,7388} & \multirow[t]{3}{*}{0,1041} & $\mathrm{R}_{20}$ & 0,0769 & 0,0080 & \multirow{3}{*}{$\begin{array}{l}\lambda_{\max }=3.061 \\
\mathrm{CR}=0.053\end{array}$} \\
\hline & & & & $\mathrm{R}_{21}$ & 0,5400 & 0,0562 & \\
\hline & & & & $\mathrm{R}_{22}$ & 0,3831 & 0,0399 & \\
\hline & \multirow[t]{2}{*}{$\mathrm{Soc}_{2}$} & \multirow[t]{2}{*}{0,2612} & 0,0368 & $\mathrm{R}_{23}$ & 0,8994 & 0,0331 & $\lambda_{\max }=2,006$ \\
\hline & & & & $\mathrm{R}_{24}$ & 0,1006 & 0,0037 & $\mathrm{CR}=0.00$ \\
\hline
\end{tabular}


The $\alpha$-cuts fuzzy comparison matrices for all level were obtained by fixing $\alpha=0.5$ and $\mu=0.5$. Some revisions of judgment with the DM were necessary as some matrices consistency ratios exceeded 0.1. Based on results shown in Table 1., among of all three key aspects the economic factor is the most significant one in selecting a 3PRL provider for this case company as it has the highest value of priority weights $\mathrm{W}=0.64$.Furthermore, under "Economic" aspect, "Overall costs" was considered the most important criterion with the total weight of 0.3267. Then the 3PRLPs should improve the price besides the other elements. "Green level" was determined as the most important sub-criteria under environmental aspect with the total weight of 0.1593. Consequently, the 3PRL providers would be better to achieve reverse logistics activities with minimum environmental impact to surpass their competitors. Moreover, in the social aspect "Customer satisfaction" is the most significant subcriterion that has to be considered by 3PRL providers.

Then the 3PRL providers are evaluated regarding each sub-criterion in order to construct the evaluation table. By using the PROMETHEE application software "Visual PROMETHEE 1.4", the outranking flows of 3PRL providers were obtained, as well as a suitable provider selected. The alternative $3 \mathrm{PRLP}_{1}$ and $3 \mathrm{PRLP}_{4}$ are incomparable as per PROMETHEE I but $3 \mathrm{PRLP}_{1}$ is superior to $3 \mathrm{PRLP}_{4}$ according to PROMETHEE II that gives the ranking in the preference order of $\mathrm{RLP}_{3}>\mathrm{RLP}_{2}>$ $\mathrm{RLP}_{1}>\mathrm{RLP}_{4}$ as shown in Fig. 2 .
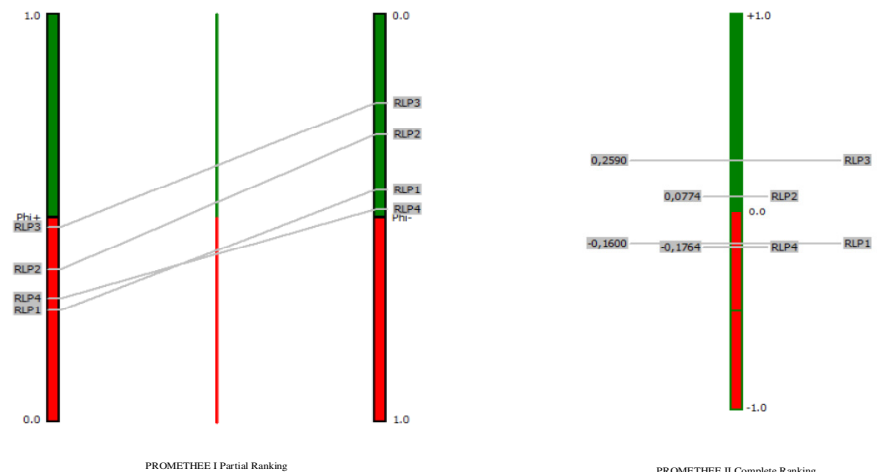

Fig. 2. PROMETHEE Ranking

The proposed approach has an advantage regarding the time and the effort of selection process compared to the existing ones.

\section{Conclusions}

This paper proposes a new integrated sustainable approach for selecting 3PRLP using AHP and PROMETHEE methods under fuzzy environment. The proposed model provides guidelines to the DM and the results obtained can help not only to select the best sustainable 3PRLP, but also to understand the current state of practice in 3PRLP selection process in the company. In our future research, this will be followed by 
GAIA plane which provides a descriptive complement vision. Sensitivity analysis of Ifwhat scenarios will be also carried to analyze the impact of changing the criteria weights on alternatives' ranking. Furthermore, the proposed approach can be illustrated by other case study using other MCDM methods like TOPSIS, VIKOR or hybrid methods and the obtained results can be compared with each other in future research.

\section{References}

1. Riopel, D., Chouinard, M., Marcotte, S., Aït-Kadi, D.: Ingénierie et gestion de la logistique inverse vers des réseaux durables. Hermes Science Publications, Lavoisier (2011)

2. Kannan, G., Pokharel, S., Sasi Kumar, P.: A hybrid approach using ISM and fuzzy TOPSIS for the selection of reverse logistics provider. Resour. Conserv. Recycl. 54, 28-36 (2009)

3. Nikolaou, I.E., Evangelinos, K.I., Allan, S.: A reverse logistics social responsibility evaluation framework based on the triple bottom line approach. J. Clean. Prod. 56, 173-184 (2013)

4. Baumann, E.: Modèles d'évaluation des performances économique, environnementale et sociale dans les chaînes logistiques (2011),

http: //tel.archives-ouvertes.fr/tel-00679706

5. Kafa, N., Hani, Y., El Mhamedi, A.: Sustainability Performance Measurement for Green Supply Chain Management. Presented at the 6th IFAC Conference on Management and Control of Production and Logistics The International Federation of Automatic Control. Center for Information Technology Renato Archer, Fortaleza, Brazil (September 11, 2013)

6. Govindan, K., Khodaverdi, R., Jafarian, A.: A fuzzy multi criteria approach for measuring sustainability performance of a supplier based on triple bottom line approach. J. Clean. Prod. 47, 345-354 (2013)

7. Wang, J., Zhu, Y.: Research on Third-party Reverse Logistics Provider Selection Based on Fuzzy Clustering in Perspective of Low-carbon Economy. Commun. Inf. Sci. Manag. Eng. 2, 63-66 (2011)

8. Tajik, G., Azadnia, A.H., Ma'aram, A.B., Hassan, S.A.H.S.: A Hybrid Fuzzy MCDM Approach for Sustainable Third-Party Reverse Logistics Provider Selection. Adv. Mater. Res. 845, 521-526 (2013)

9. Kafa, N., Hani, Y., El Mhamedi, A.: Sustainable approach for third-party reverse logistics provider selection. Presented at the International Conference on Green Supply Chain, Arras, France (June 25, 2014)

10. Saaty, T.L.: The analytic hierarchy process. McGraw-Hill Book Co., New York (1980)

11. Kwong, C.K., Bai, H.: A fuzzy AHP approach to the determination of importance weights of customer requirements in quality function deployment. J. Intell. Manuf. 13, 367-377 (2002)

12. Zadeh, L.A.: Fuzzy sets. Inf. Control. 8, 338-353 (1965)

13. Lee, A.R.: Application of modified fuzzy ahp method to analyze bolting sequence of structural joints (1995), http: / / dl .acm.org/citation. cfm?id=922586

14. Brans, J.-P., Vincke, P.: A preference ranking organization method: the PROMETHEE method for MCDM. Manag. Sci. 31, 641-656 (1985)

15. Chen, S.H., Hsieh, C.H.: Representation, ranking, distance, and similarity of L-R type fuzzy number and application. Aust. J. Intell. Process. Syst. 6, 217-229 (2000)

16. Gupta, R., Sachdeva, A., Bhardwaj, A.: Selection of logistic service provider using fuzzy PROMETHEE for a cement industry. J. Manuf. Technol. Manag. 23, 899-921 (2012) 